http://jmscr.igmpublication.org/home/

ISSN (e)-2347-176x ISSN (p) 2455-0450

crossref DOI: https://dx.doi.org/10.18535/jmscr/v8i1.107

Journal Of Medical Science And Clinical Research

\title{
Reference Interval of Plasma Urea in a Port Harcourt Population: A Retrospective Study
}

\author{
Authors \\ Dr Frederick Igila Allison ${ }^{1}$, Dr Aaron C Ojule ${ }^{1}$ \\ ${ }^{1}$ Department of Chemical Pathology, University of Port Harcourt \\ Port Harcourt, River state, Nigeria
}

\begin{abstract}
Introduction: A reference interval is very important in the practice of laboratory medicine as medical personnel depend on this to make diagnosis, treat and monitor patients. An accurately determined reference interval of a population can be said to be the first step to patient care. More so, reference intervals need to be periodically reviewed due to population dynamics.

Aim: To determine the current reference interval of urea and to compare same with the previously determined interval here and that presently in use in our laboratory.

Methods: Urea results of patients who were non diabetic, non-hypertensive and had no cardiac or renal disorders were obtained for a period of three months. These results were ranked and the mean determined. The nonparametric method was used to determine the reference interval from the data.

Result: The mean urea result was $2.6 \mathrm{mmol} / \mathrm{l}$ and the reference interval was $1.2-3.6 \mathrm{mmol} / \mathrm{l}$

Conclusion: The reference interval so generated $(1.2-3.6 \mathrm{mmol} / \mathrm{l})$ is clinically about the same with that generated about twenty years ago $(1.2-3.9 \mathrm{mmol} / \mathrm{l})$ and both are significantly different from that in use in our laboratory (2.4-6.2mmol/l). The use of this current reference interval will therefore improve interpretation of urea results in our area.

Keywords: Non Parametric, Reference Interval, Diacetyl monoxine.
\end{abstract}

\section{Introduction}

Urea is produced primarily in the $\operatorname{liver}^{1}$ and carried in blood to the kidney where it is excreted. Urea is mainly excreted by the kidney ${ }^{2}$ with a small percentage excreted in sweat ${ }^{3}$. Factors like protein intake, kidney and liver functional status as well as age of subjects, to a large extent, determine the concentration of blood urea ${ }^{4}$. Blood urea estimation may be used for routine investigation, during emergencies and as well as provide clues to various clinical presentations that could be as a result of bio-chemical imbalance. These have made urea estimation and interpretation of its result very vital parameters in medical practice. Since a rightly interpreted result starts with a rightly determined reference interval, the determination of the reference interval of urea cannot be over emphasized. Social and economic dynamics of a population may positively or negatively influence the quality of diets of the population; in this case the amount of protein ingested, as these affect blood urea concentration. As new instruments are acquired or new methods introduced in the laboratory, reference intervals generated through old instruments/methods should be reviewed. Apart from these above mentioned 
factors, laboratories are also encouraged to determine their own population based reference intervals and periodically review those in existence $^{5}$. These factors and the dynamic nature of the socio economic indices have therefore made it necessary to review the urea reference interval in our centre since the one in use is from manufacturer's kits, and that determined locally in 1997 was not introduced for use in the laboratory.

\section{Methods}

This was a retrospective study where about 1840 urea results of patients who were not hypertensive, diabetic and did not have renal or kidney problems were collected from the chemical pathology laboratory of the University of Port Harcourt Teaching Hospital. All patients who met these criteria were selected for the study within the stipulated period of three months. The nonenzymatic diacetyl monoxine method ${ }^{6}$ is used routinely to estimate patient's plasma urea concentration by the laboratory and this method was used to generate the results. Data collected were ranked and outliers removed using the Dixon outlier statistic ${ }^{7}$. The mean age of subjects as well as the mean, median and mode of these results were determined. The non-parametric method was used to determine the reference interval since the data was skewed.

\section{Results}

A total of 1840 patients' with ages ranging from 3years to 80 years who met the inclusion criteria had their urea results selected for this study. (Table1) The results were ranked and outliers removed using Dixon method. The mean age of the reference population was 45.2 years. The lowest and highest urea values were $1.2 \mathrm{mmol} / 1$ and $5.2 \mathrm{mmol} / \mathrm{l}$ which gave a range of 4.0 and a urea mean of $2.6 \mathrm{mmol} / \mathrm{l}$.(Table1) The nonparametric method was used to determine the reference interval and this was because the data was skewed. The $2.5^{\text {th }}$ and $97.5^{\text {th }}$ percentile were used as the lower and the upper limits of the reference interval. This gave a plasma urea reference interval of 1.2-3.6mmol/l. (Table 1)

Table 1: Plasma Urea Concentration of Study Subjects

\begin{tabular}{|l|c|}
\hline Number of subjects & 1840 \\
\hline Number of females & 900 \\
\hline Number of males & 940 \\
\hline Youngest subject (years) & 003 \\
\hline Oldest subjects (years) & 080 \\
\hline Mean age (years) & 45.2 \\
\hline Lowest urea value (mmol/l) & 1.20 \\
\hline Highest urea value $(\mathrm{mmol} / \mathrm{l})$ & 5.20 \\
\hline Urea mean concentration $(\mathrm{mmol} / \mathrm{l})$ & 2.60 \\
\hline Ref interval of urea $(\mathrm{mmol} / \mathrm{l})$ & $1.2-3.6$ \\
\hline
\end{tabular}

Table 2: Mean plasma urea concentration across age groups

\begin{tabular}{|l|c|}
\hline Age group (yrs) & urea $(\mathrm{mmol} / \mathrm{l})$ \\
\hline $10-19$ & $2.8 \pm 0.8$ \\
\hline $20-29$ & $2.8 \pm 0.7$ \\
\hline $30-39$ & $2.8 \pm 0.8$ \\
\hline $40-49$ & $2.8 \pm 0.8$ \\
\hline $50-59$ & $3.0 \pm 0.7$ \\
\hline $60-69$ & $3.0 \pm 0.7$ \\
\hline $70-79$ & $3.4 \pm 0.9$ \\
\hline ANOVA & $0.9999^{* *}$ \\
\hline
\end{tabular}

Difference across age groups is not statistically significant ( $\mathrm{p}$-value 0.05)

\section{Discussion}

Blood urea concentration to a large extent depends on the amount of protein in the diet of the individual subject, the liver and renal functions ${ }^{8}$. This is because urea is produced mainly by the liver and excreted by the kidney. A small fraction of urea produced can also be excreted in sweat. A previous study carried out in Port Harcourt showed a gradual decrease in the mean of blood urea over some years ${ }^{9}$. This was linked to the waning socio-economic status of the people of Port Harcourt and Nigeria as a whole ${ }^{9}$. It was believed that the economic reality directly reflected on the nutritional factor [protein intake] of the reference population. The mean plasma urea of the reference population in that study was noted to systematically drop from $4.4 \mathrm{mmol} / \mathrm{l}$ in 1983 to $2.4 \mathrm{mmol} / 1$ in 1997 and the reference interval so determined in that study was $1.2-3.9 \mathrm{mmol} / \mathrm{l}^{9}$. The systematic yearly drop notice in that study was 
attributed to the increasing economic hardship of the times, which was believed to result in reduced protein intake.

In this present study, the mean plasma urea was $2.6 \mathrm{mmol} / \mathrm{l}$ and the reference interval was 1.2 $3.6 \mathrm{mmol} / \mathrm{l}$. (Table1) This had a slightly lower upper limit than the previous reference interval, even though the urea mean in this study was higher than the urea mean of the reference population of the previous study, which was $2.4 \mathrm{mmol} / \mathrm{l}^{9}$. This slight difference in the upper reference limit could be due to the size of the reference population which was 100 in the 1997 study but 1840 for this study.

Apart from the size of the reference population, the age range of the reference population of this study was wider. In this study, the age range was from 3years to 80 years while the previous study had an age range from 18- 24 years with a mean age of 22.4 years. The mean age of the subjects in this present study was 46.6 years. Studies have shown that blood urea concentration increases with age ${ }^{10}$. This is believed to be largely due to the fact that organ functions are believed to reduce with age, ${ }^{11}$ and protein intake has also been shown to be reduced in the elderly ${ }^{10}$. The increase in blood urea in the elderly can only be due to reduce GFR leading to reduced urea excretion. These facts can explain the findings seen in this study (table2), which showed a gradual increase in the mean urea concentration across the age range. There was a steady urea concentration from 10 to 40 years of age and a gradual increase from 40 years to 70 years, though the differences in the mean concentrations were not statistically significant (table 2).

Since in this study the reference population was older, this could explain why the mean urea concentration was slightly higher. These arguments for and against increased blood urea concentration in the elderly, has made the most likely explanation for this disparity in the upper reference limit of the two studies to be largely due to the size of the reference population.
The reference interval presently in use in our laboratory is $2.4-6.2 \mathrm{mmol} / \mathrm{l}$, which was from literature inserts in the commercial kits used for urea estimation. This means that, 20 years after the first Port Harcourt study, the reference interval so determined was yet to be introduced to the laboratory for use. This could explain the discrepancies in the urea and creatinine results from same sample produced by the laboratory making it sometimes difficult for easy interpretation of urea results. This discrepancy noticed even before the first Port Harcourt study about twenty years ago, is still being observed. This is because the reference intervals presently used in our laboratory are still those of literature which was generated from Caucasians with higher protein intake. Studies have shown that Africans generally have lower plasma urea concentration, primarily due to lower protein $\operatorname{diet}^{9}$. The reference range so generated in this study is clinically about the same with that generated about 20 years ago and these are statistically and clinically different from that presently used in our laboratory and those from studies done on Caucasians ${ }^{12,13}$. The introduction of this reference interval to the laboratory will improve the interpretation of parameters for renal function and the overall patient care in this environment. It is therefore advocated that each laboratory each laboratory should generate its reference intervals and review them periodically for better clinical care.

\section{Conclusion}

The reference interval generated in this study was about the same with that generated about twenty years ago in our laboratory but statistically different from that presently in use in the laboratory. The introduction of this reference interval for use in our hospital may rectify the discrepancy between creatinine and urea results thereby improving the interpretation of results of renal function and overall clinical management of subjects in this region. 


\section{References}

1. Weiner ID, Mitch WE, Sands JM.Z Urea and ammonia metabolism and the control of renal nitrogen excretion. CJASN 2015; 10, 8: 1444-1458.

2. McWilliam A, Macnab R. Laboratory tests of renal function. Anaesthesia \& Intensive Care Medicine 2009; 10, 6: 296-99.

3. Frankenfield DL, McClellan WM, Helgerson SD, Lowrie EG, Rocco MV, Owen WF. Relationship between urea reduction ratio, demographic characteristics, and body weight for patients in the 1996 National ESRD Core Indicators Project'. American Journal of Kidney Disease 199933(3):584-91.

4. Hoang K, Tan JC, Derby G, Blouch KL, Masek M, Ma I. Determinants of glomerular hypo filtration in aging humans, Kidney International 2003; 64(4):1417- 1424.

5. Horn, P.S., Feng, L., Li, Y. \& Pesce, A.J. (2001), 'Effect of outliers and nonhealthy individuals on reference interval estimation,' Clinical Chemistry 2001;47 (12): 2137-2145.

6. Huang, X., Li, S., Yang, X., Peng, Q., Wang, J. \& Mo, C. (2014), Establishing reference values for blood urea and serum creatinine in Chinese Han ethnic adult men. Clin Lab, 60(7):1123-1128.

7. Marsh WH, Fingerhut B, Miller $\mathrm{H}$. Automated and manual direct methods for the determination of blood urea. Clinical Chemistry 1965;11: 624-627

8. Traynor J, Mactier R, Fox GJ. How to measure renal function in clinical practice. BMJ 2006; 333(7571): 733-737.

9. Ojule AC, Onah AI, Rukari AI. Plsmas Urea in a Reference Population in Port Harcourt. Postgrad Med J 1999; 6(4):167170.

10. Schneider F, Maurer C, Friedberg RC. International Organization for Standardization (ISO) 15189, Annals of
Laboratory Medicine2017; 37(5): 365370.

11. Sullivan, L.P., \& Granthan, J.J. (1982), 'Physiology of the kidney $2^{\text {nd }}$ Edition. Lea and febiger. Philadelphia, P68.

12. Traynor J, Mactier R. Fox GJ. 'How to measure renal function in clinical practice', British Medical Journal2006; 333(7571): 733-73.

13. Weiner ID, Mitch WE, Sands JMZ. 'Urea and ammonia metabolism and the control of renal nitrogen excretion', Clinical Journal of American Society Nephrology 2015; 10 (8): 1444-1458. 